\title{
The Mediating Effects of Vocabulary between Morphological Awareness and Reading Comprehension in School-aged Children
}

\author{
Bhuja Chung \\ Department of Speech-Language Pathology, Chosun University, Gwangju, Korea
}

Correspondence: Bhuja Chung, $\mathrm{PhD}$ Department of Speech-Language Pathology, Chosun University, 309 Philmundae-ro, Dong-gu, Gwangju 61452, Korea

Tel: +82-62-230-7858

Fax: +82-62-230-6271

E-mail: bjchung@chosun.ac.kr

Received: April 5, 2020

Revised: April 27, 2020

Accepted: May 4, 2020

This work was supported by research fund from Chosun University, 2019

\begin{abstract}
Objectives: Morphological awareness refers to the ability to recognize and manipulate the smallest meaningful structure of words. Recent studies have shown that morphological awareness is particularly relevant for understanding language development, especially vocabulary knowledge, and reading skills. The purpose of this study was to investigate the mediating effect of vocabulary knowledge on the relationship between morphological awareness and reading comprehension. Methods: Participants in this study were 278 children in first through sixth grade of two elementary schools in a Metropolitan city. Tests of morphological awareness on derived affixes, receptive vocabulary and reading comprehension were carried out. In order to estimate the mediating effect, correlation analysis and regression analysis were conducted using the Baron \& Kanny and Sobel test. Results: In our results, morphological awareness significantly predicted reading comprehension. The partial mediating effect of vocabulary was also showed throughout the elementary grade group. Conclusion: Our findings show that morphological awareness contributes to reading comprehension indirectly through language systems such as vocabulary knowledge. These results suggested that skilled morphological awareness competence may have an impact on enhancing vocabulary acquisition and eventually academic reading skills which are based on language skills. Also, the need for vocabulary intervention, including deep and rich morphological instruction, was discussed. Limitations and suggestions were also added.
\end{abstract}

Keywords: Mediating effects, Reading comprehension, Vocabulary, Morphological awareness, School-aged children 형태인식(morphological awareness)이란 언어의 형식과 구조를 이해하고, 분석하며, 의미를 적용하는 능력을 가리킨다(Apel \& Diehm, 2014; Carlisle, 2010; Gibson \& Wolter, 2015). 음운인식이 단어를 구성하는 말소리를 구별하고 조작하는 메타언어 능력이라 면, 형태인식은 단어 내 최소 ‘의미’ 단위인 형태소를 의식적으로 인 지하고 다루는 메타언어 능력이다. 이처럼 단어의 의미와 관련된 속성 때문에 형태인식은 어휘발달 및 언어기반 문해능력에 관한 연 구 주제의 하나로 꾸준히 다루어졌다(Apel \& Lawrence, 2011; Bowers \& Kirby, 2010; Kirby, Desrochers, Roth, \& Lai, 2008; Nagy, Berninger, \& Abbott, 2006; Ramirez, Walton, \& Roberts, 2013). 새롭
고 복잡한 단어를 형성하는 방식은 마치 구슬을 꿰듯 형태소들을 체계적으로 나열하는 단순한 과정이 아니다. 복잡한 단어일수록 포함된 음소변이 특성으로 인한 음운 변동성, 단어배열에 관한 통 사 규칙과의 관련성 등이 더 많아지고 그에 더해 형태소 각각이 지 닌 의미 표상들이 서로 상호작용하며 처리된다.

우리가 형성하고 표현하는 단어나 문장들은 어휘나 구문의 형식 으로 기억 속에 그대로 저장되지 않으며 그러한 저장이 가능 하지 도 않다. 즉, 접사나 어미, 관용구나 숙어 등 크고 작은 단위의 형태 로 저장된 단어들이 발화과정에서 인출되고 결합되면서 다양한 형 태 혹은 구문 규칙에 의해 창조되며 표현되는 것이다. 이렇게 언어 
구조를 고려하고 조작하는 능력인 메타언어인식은 아동이 언어의 형식과 의미의 복잡한 관계를 의식적으로 이해하기 시작하는 시기 인 학령기 이후에 구체적으로 발달하면서 극적으로 증가한다(Anglin, 1993). 이러한 증가는 어근이나 접사와 같은 개별 단어에 대한 아동의 지식이 증가하기 때문이기도 하지만 단어내의 형태적 구성 요소를 분석함으로써 복잡한 단어를 유추하거나 조작하는 능력, 곧 형태인식 전략이 세련되어지기 때문이기도 하다. Carlisle (2010) 은 "언어 형식과 의미 간의 관계에 대한 민감도가 형태인식의 특 징” 임을 지적하면서 형태인식 중재가 “단어 구조, 철자, 의미의 관 계를 분석하는 습관을 발달시키고, 이러한 습관은 어휘, 단어재인, 철자쓰기, 그리고 텍스트에 대한 깊이 있는 이해에 도움"을 줄 것이 라고 의미를 부여하였다(p. 467). 형태인식과 어휘와의 관련성에 관 한 연구는 영어사용 아동(Bowers \& Kirby, 2010; Ramirez et al., 2013; Sparks \& Deacon, 2015)뿐 아니라 어휘지식이 부족할 수 있 는 이중언어나 다문화가정 배경 아동(Chung \& Shim, 2019; Kieffer \& Lesaux, 2012; Zhang, 2014)을 대상으로 폭넓게 진행되었다. 연구 결과들은 형태인식에서 증가율을 보인 학생들이 어휘지식에서도 높은 성장을 보였으며 그러한 성장은 고학년까지 지속되는 경향을 나타냈다고 보고하였다. 음운인식, 단어재인과 같은 요인의 성장이 중학년 이후주춤해지는 것을 고려할 때(Chung \& Yoon, 2019; Kieffer \& Lesaux, 2012) 이러한 증가율은 어휘와 형태인식 간의 강한 관 련성을 지지한다고 해석될 수 있다.

읽기자료를 이해하기 위해 우선적으로 중요한 요건은 풍부한 어 휘지식일 것이다. Nagy와 Scott (2000)은 읽기자료에 있는 어휘의 $90 \%$ 정도를 알고 있어야 나머지 $10 \%$ 를 추론함으로써 해당 자료를 이해할 수 있다고 설명하였다. 더욱이 최근 연구들은 풍부한 어휘 지식뿐 아니라 어휘에 대한 깊이 있는 이해라는 질적 측면이 읽기이 해능력을 예측하는 더 유의한 변인이라고 밝히면서(Cain \& Oakhill, 2014; McKeown, Beck, Omanson, \& Perfetti, 1983; Yoon, Pae, \& Chung, 2018), 단어에 관한 정의, 반의어 및 동의어와 함께 형태 인식이 어휘 깊이를 측정하는 요인이라고 설명하고 있다(Binder, Cote, Lee, Bessette, \& Vu, 2017). Nagy 등(2006)은 4학년에서 9학 년 학생을 세 집단으로 나누어 횡단연구를 실시한 결과, 형태인식 이 읽기이해에 직접적으로 영향을 미치기도 하지만 어휘력의 증진 에 유의하게 관여함으로써 읽기이해력의 증진에 기여한다고 결론 지었다. 즉, 형태론적 지식이 복잡한 형태구조를 지닌 단어에서 파 생되는 의미를 분석하도록 도움으로써 구어와 문어 간의 의미망을 촉진하고, 궁극적으로 텍스트를 이해하는데 영향을 미치는 주요 역할을 한다는 것이다(Perfetti, Landi, \& Oakhill, 2005). Levesque, Kieffer와 Deacon (2017)은 다변량 경로분석을 실시하여 형태인식
이 읽기이해에 직접적으로 영향을 줄 뿐 아니라 단어읽기와 형태론 적 분석을 통해 읽기이해에 간접적으로 기여하였다고 보고한 바 있 다. Deacon, Kieffer와 Laroche (2014) 역시 단어읽기가 형태인식과 읽기이해를 부분 매개한다고 보고하면서 이러한 결과는 초등 저학 년만을 대상으로 하였기에 넓은 학년군을 포함하는 후속 연구를 통해 좀 더 포괄적인 언어시스템으로서 형태인식이 읽기이해에 어 떻게 영향을 미치는지 파악할 필요가 있다고 논의하였다. 형태인식 이 읽기이해, 단어읽기, 철자 및 해독 등의 문해요소들에 미치는 영 향에 관하여 연구한 Nagy 등(2006)도 해독 및 비단어 반복과 관련 한 검사에서는 학년 간 편차가 컸으나 형태인식과 어휘 간의 관련 성은 전 학년에 걸쳐 꾸준히 유의하였다고 보고한 바 있다. 또한 구 조방정식 분석을 통해 형태인식이 어휘력 성장에 관여하며 이를 통 해 읽기이해에도 상당한 기여를 하였음을 밝혀주었다. 따라서, 본 연구에서는 읽기이해에 미치는 어휘력의 영향력(Roth, Speech, \& Cooper, 2002; Storch, \& Whitehurst, 2002)이 전체 학년을 대상으 로 할 때 매개 변인으로서 어떤 효과를 지니는지 구체적으로 탐색 할 필요가 있다고 판단하였다.

본 연구는 선행연구 결과를 기반으로 형태인식이 읽기이해에 직 접 기여하지만, 어휘력에도 영향을 미치고 이를 통해 읽기이해에 대 한 매개효과를 지닐 것이라는 가정을 채택하였다. 이를 탐색하기 위해 굴절형태소보다는 단어의 형성과정에 좀 더 직접적으로 관여 하는 파생형태소(Hoff, 2014)를 활용한 형태인식검사를 적용하였 다. 연구를 통해 밝혀진 결과는 학령기 아동의 읽기이해를 증진하 기 위한 다양한 교육 및 중재프로그램을 구성하는데 기초자료를 제공하리라 기대되었다. 본 연구를 위한 구체적인 연구문제는 다음 과같다.

첫째, 초등학생이 보인 형태인식과 읽기이해간의 관계는 어떠한가? 둘째, 초등학생이 보인 형태인식과 읽기이해의 관계에서 어휘력 의 매개효과는 어떠한가?

\section{연구방법}

\section{연구대상}

본 연구는 광주광역시 소재 초등학교에 재학중인 1학년에서 6 학년 아동을 대상으로 하였다. 연구 분석 대상의 배제기준은 (1) 학 부모 및 교사로부터 검사 당시 특수교육서비스를 받고 있거나감각, 정서, 청각 및 신경의 문제가 있다고 확인된 아동, (2) 한국 비언어지 능검사 2판(K-CTONI-2, Park, 2014)의 도형척도 소검사 결과 지능 지수가 70 이하에 해당하는 아동이었다. 이는 아동을 대상으로 한 대규모 선행연구(Tambyraja, Schmitt, Farquharson, \& Justice, 
Table 1. Descriptive statistics for the variables ( $N=278)$

\begin{tabular}{|c|c|c|c|c|c|c|}
\hline Variables & Min & Max & Mean & SD & Skew. & Kurt. \\
\hline Nonverbal IQ (K-CTONI-2) & 73.00 & 135.00 & 100.44 & 11.80 & .349 & -.352 \\
\hline Reading comprehension (KOLRA-RC) & .00 & 23.00 & 10.83 & 6.01 & -.142 & -.953 \\
\hline Vocabulary (REVT-R) & 26.00 & 178.00 & 100.97 & 24.68 & .201 & .284 \\
\hline Morphological awareness & .00 & 20.00 & 12.03 & 5.60 & -.80 & -.34 \\
\hline
\end{tabular}

All reported sores are raw scores except for Nonverbal IQ scores.

K-CTONI-2 = Korean Comprehensive Test of Nonverbal Intelligence-second edition (Park, 2014); REVT-R=Receptive \& Expressive Vocabulary Test-Receptive subtest (Kim et al., 2009); KOLRA-RC=Korea Language-based Reading Assessment-Reading Comprehension subtest (Pae et al, 2015).

2015 참조)를 참고한 것으로 분석에 영향을 미치는 극단 값을 배제 하기 위함 이었다. 그 결과 최초 검사 대상이었던 316 명 중 위 기준 에 적합하지 않은 아동 9명과 검사 시 개인적인 사유로 모든 검사 를 완료하지 못한 아동 29명이 제외되어 최종적으로 278명(1학년 77명, 2학년 36명, 3학년 77명, 4학년 50명, 5학년 18명, 6학년 20명) 이 분석대상에 해당하였다. 검사대상 아동의 지능 및 측정 변인 검 사점수에 관한 전반적인 기술통계 결과는 Table 1에 제시하였다.

\section{검사도구}

\section{읽기이해 검사}

본 연구에서는 검사유형에 따른 변인 간의 예측력의 차이를 탐 색한 관련 선행연구(Chung, Kim, \& Yoon, 2017)를 참고로 한국어 읽기검사(KOLRA; Pae, Kim, Yoon, \& Jang, 2015)의 하위검사 중 읽기이해검사를 사용하여 측정하였다. KOLRA의 읽기이해검사는 문장 및 짧은 문단 글을 읽고 빈칸을 채우는 형식이며 총 24개 문항 으로 다르게 구성되어 있다.

\section{어휘력}

대상 아동의 어휘력 측정에는 수용 - 표현어휘력 검사(REVT; Kim, Hong, Kim, Jang, \& Lee, 2009)의 수용어휘력 하위검사를 사 용하였다. Kieffer와 Lesaux (2012)가 사용한 수용어휘 검사의 경우 연구대상인 5,6 학년 아동이 응답한 단어의 $50 \%$ 정도가 형태적으 로 복잡한 파생어나 굴절어였다. REVT 수용어휘력 하위검사의 경 우 전체 185 개 어휘 중 $52 \%$ 에 해당하는 약 97 개가 복합어로서 파생 어(예: 엿보다)나 합성어(예: 전등불)이므로 어휘지식을 측정하는 검사에 적합하다고 판단하였다.

\section{형태인식 검사}

본 연구에서는 굴절형태소보다 단어의 형성과정에 좀 더 직접적 으로 관여하는 것으로 밝혀진 파생형태소(Hoff, 2014)를 활용한 형 태인식 검사를 적용하였다. 해당 검사는 국외 선행연구를 바탕으
로 Chung (2016)이 제작한 후, 예비검사(Chung \& Shim, 2019 자 료)에서 얻은 자료에 jmetrix를 이용한 문항분석을 실시한 후 난이 도를 고려하여 문항을 선별한 파생어 형태인식 검사이다. 해당 검 사에는 두 가지 유형의 검사가 포함되었는데, A:B::A'B' 형식의 유 추검사(Casalis, Deacon, \& Pacton, 2011; Deacon \& Kirby, 2004; Tong, Deacon, Kirby, Cain, K.,\& Parrila, 2011)는 '물건을 팔다:팔 기'의 예시를 보고 '가방을 놓다:____'에 '놓기'라는 파생어를 유추 하거나, '아직 덜 익은 사과: 풋사과’의 예에 맞게 '아직 익지 않은 고 추: ____'의 빈칸에 '풋고추'를 유추하는 방식의 검사이다. 변환검 사(Apel \& Lawrence, 2011; Berninger, Abbott, Nagy, \& Carlisle, 2010)는 제시된 단어를 문장에 맞게 형성하는 과제로서 '접다/미술 시간에 종이_____를 했다'가 제시되면 '접기'라는 파생어로 변환 하는 방식이다. Chung (2016)은 파생어 형태인식 검사를 유추검사 2 개와 변환검사 1 개로 나누었고, 검사 당 의미파생어와 무의미파생 어로 구분하여 총 6 개 하위검사를 구성한 후 이를 변인으로 문항내 적일관성 신뢰도를 측정하였고 .904의 Cronbach $\alpha$ 값을 보고하였 다. 형태인식검사는 유추검사 14 문항, 변환검사 6 문항 총 20 문항이 며, 아동의 읽기수준을 고려하여 모든 문항을 음성 녹음한 후 노트 북이나아이패드를 통해 읽기자료와 동시에 제시하였다.

\section{검사절차}

본 연구자가 속한 학과와 $\mathrm{MOU}$ 를 맺은 2개 초등학교를 방문하 여 검사를 실시하였다. 담임교사 및 보호자의 동의를 얻은 후 초등 학교 내 도서관, 과학실과 방과 후 교실 등의 조용하고 분리된 장소 에서 일대일 검사 형식으로 진행하였다. 아동의 협조를 격려하기 위해 검사를 마칠 때마다 스티커를 제공하였으며 검사결과는 추후 담임교사에게 해석지와 함께 전달하였다. 연구보조원은 언어치료 학과 학부 4 학년, 대학원 석사 및 박사과정 재학생으로 연구자가 검 사 실시 및 해석에 관하여 충분한 교육을 실시하였고 검사에 익숙 해 지도록 교육 후 수 차례에 걸쳐 짝 지어 검사도구를 실습하였다. 또한 검사의 신뢰도를 높이기 위해 보조원마다 동일한 검사를 실 
시하도록 배정하였으며 검사 순서는 무선적으로 진행하였다.

\section{통계처리}

본 연구에서는 먼저 각 학년 별로 검사결과의 분포를 확인하기 위해 첫째, 대상 아동 자료의 기술통계치(최소값, 최대값, 평균, 표 준편차, 왜도, 첨도)를 산출하였고 측정도구의 신뢰도 값과 각 측정 변인 간의 상관분석을 실시하였다. 둘째, 형태인식 검사 점수와 읽 기이해 점수의 관계에서 어휘력이 매개역할을 하는지 살펴보기 위 해 Baron과 Kenny (1986)가 제안한 회귀분석을 사용한 매개변인 검증절차를 적용하였다. 동시에 다중공선성을 확인하기 위해 변인 간의 분산팽창계수(variance inflation factor, VIF)와 회귀모형의 안정성을 확인하는 Durbin-Watson 값을 함께 구하였다. VIF는 1 에 근접할수록, Durbin-Watson 값은 2에 근접할 수록 회귀계수 모형의 안정성을 나타내므로 이를 확인하는 것이 필요하다고 판단 되었다. 셋째, 매개모형이 완전 매개인지 부분 매개인지를 살펴보았 다. 매개변수의 동시 투입으로 인해 독립변인이 종속변인에 대해 가 지는 영향력이 사라지는 경우 매개변인은 독립변인을 완전 매개한 것이라고 볼 수 있으며, 독립변인의 영향력이 여전히 유의하거나 감 소하는 경우 매개변인은 독립변인과 종속변인의 관계를 부분 매개 한 것이라고 볼 수 있기 때문이다. 모든 통계처리에는 IBM SPSS version 23 (IBM, Armonk, NY, USA)을 사용하였다. 넷째, Sobel Test를 실시하여 분석된 매개효과의 통계적 유의성을 검증하였다.

Table 2. Correlations among variables

\begin{tabular}{lccc}
\hline Variables & 1 & 2 & 3 \\
\hline 1. Reading comprehension (KOLRA-RC) & 1 & & \\
2. Vocabulary (REVT-R) & $.747^{* * *}$ & 1 & \\
3. Morphological awareness & $.695^{* * *}$ & $.570^{* * *}$ & 1 \\
\hline
\end{tabular}

${ }^{* * *} p<.001$.

\section{연구결과}

본 연구에서 초등학생을 대상으로 실시한 읽기이해 및 관련 변인 의 점수에 관한 기술통계 결과는 Table 1 에, 변인 간의 상관계수는 Table 2 에 제시하였다. 주요 변인의 왜도는 절대값 2 를 넘지 않았고, 첨도 또한 절대값 7을 넘지 않아 모든 변인이 정규성을 만족하는 것 으로 분석되었다.

\section{형태인식, 어휘력, 그리고 읽기이해 간의 관계}

회귀분석에 앞서 독립, 매개, 종속변인 간의 관계를 살펴보고 매 개효과 검증의 필요성을 탐색하고자 상관관계 분석을 실시하였다. 그 결과 Table 2 와 같이 형태인식은 어휘와 유의한 정적 상관관계 를 보였으며 $(r=.570, p=.000)$, 형태인식과 읽기이해 간에도 정적인 상관관계가 유의하게 나타났다 $(r=.695, p=.000)$. 또한 어휘와 읽 기이해 간의 상관도 정적으로 높게 나타났다 $(r=.747, p=.000)$.

\section{형태인식과 읽기이해에 대한 어휘력의 매개효과}

형태인식과 읽기이해의 관계에서 어휘력의 매개효과를 검증하 기 위해 Baron과 Kenny (1986)가 제시한 분석방식에 따라 매개효 과 탐색을 위한 위계적 회귀 분석을 실시하였으며 그 결과는 Table 3 과 같다. 분석결과 모든 모형단계에서 VIF와 Durbin-Watson 값 은 각각 1 과 2에 근접한 것으로 나타나 변량의 선형성을 알 수 있는 다중공선성과 회귀모형의 안정성은 충족된 것으로 분석되었다.

첫 단계에서 수정된 $\mathrm{R}^{2}$ 의 값에 의한 형태인식과 읽기이해 간의 모형의 설명력은 $32 \%$ 로 나타났고, 검정 통계량에 의한 모형도 유의 한 것으로 나타났다 $\left(F_{(1,276)}=132.588, p=.000\right)$. 형태인식이 어휘력 에 영향을 미치는지 검증하기 위한 단순회귀분석 결과에서도 그 영향력은 유의한 것으로 나타났다 $(\beta=.570, p=.000)$. 다음으로, 형 태인식이 읽기이해에 미치는 영향력에 관한 분석결과 모형의 설명 력은 $48 \%$ 로 유의하게 나타났고 $\left(F_{(1,276)}=257.531, p=.000\right)$ 그 영향

Table 3. Analysis of mediating effects of vocabulary between morphological awareness and reading comprehension

\begin{tabular}{|c|c|c|c|c|c|c|}
\hline Step & B & S.E & $\beta$ & $\mathrm{t}$ & $R^{2}$ & $F$ \\
\hline $\begin{array}{l}1 \text { step (Independent } \rightarrow \text { Mediator) } \\
\text { MA } \rightarrow \text { Voc. }\end{array}$ & 2.511 & .218 & .570 & $11.515^{* * *}$ & .322 & $132.588 * * *$ \\
\hline $\begin{array}{l}2 \text { step (Independent } \rightarrow \text { Dependent) } \\
\quad \mathrm{MA} \rightarrow \mathrm{RC}\end{array}$ & .746 & .047 & .695 & $16.048^{* * * *}$ & .481 & $257.531 * * *$ \\
\hline $\begin{array}{l}3 \text { step (Independent, Mediator } \rightarrow \text { Dependent) } \\
\text { MA } \rightarrow \text { RC } \\
\text { Voc. } \rightarrow \mathrm{RC}\end{array}$ & $\begin{array}{l}.428 \\
.127\end{array}$ & $\begin{array}{l}.046 \\
.010\end{array}$ & $\begin{array}{l}.399 \\
.520\end{array}$ & $\begin{array}{r}9.391^{* * *} \\
12.243^{* * *}\end{array}$ & .663 & $273.164^{* * *}$ \\
\hline
\end{tabular}

MA=Morphological Awareness; Voc. =REVT-R(Receptive \& Expressive Vocabulary Test-Receptive subtest); RC=KOLRA-RC(Korea Language-based Reading AssessmentReading Comprehension subtest).

${ }^{* * *} p<.001$. 


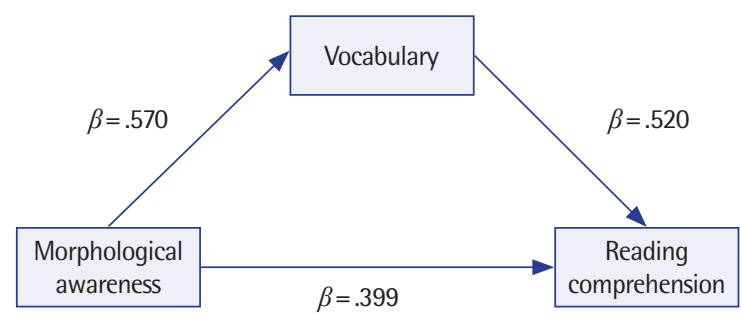

Figure 1. Partial mediating effects of vocabulary between morphological awareness and reading comprehension.

력 또한 통계적으로 유의하였다( $\beta=.047, p=.000)$. 마지막으로 형 태인식과 어휘력이 읽기이해를 예측하지만 어휘력의 효과를 통제 했을 때 형태인식의 영향력은 어떠한지 확인하였다. 그 결과 Table 3 에 나타난 바와 같이 매개변인으로 상정한 어휘력의 효과를 통제 한 후에도 그 효과가 다소 감소하였지만 형태인식은 읽기이해를 통 계적으로 유의하게 예언하였고( $\beta=.399, p=.000)$ 독립변인이면서 매개변인인 어휘력 또한 읽기이해를 유의하게 예언하였다 $(\beta=.520$, $p=.000)$. 결과를 종합하면 어휘력의 효과를 통제하였을 때 형태인 식이 읽기이해에 미치는 영향력의 효과는 여전히 존재하지만 감소 하였고, 이에 따라 어휘력이 형태인식과 읽기이해를 부분 매개하는 것을 알 수 있었다. 마지막 3단계 모형에서 형태인식과 어휘력이 동 시에 읽기이해를 설명하는 크기는 $66 \%$ 로 나타났다.

위에서 분석된 매개효과의 유의성을 검증하기 위해 Sobel Test를 수행한 결과 $Z$ 값은 8.532 로 그 매개효과가 유의한 것으로 확인되었 다 $(p=.000)$. 전체적인 분석결과 선행연구를 바탕으로 본 연구에서 채택한 가정인 형태인식이 어휘력의 증가에 관여하며, 어휘력을 매 개로 읽기이해에도 영향을 미칠 것이라는 가설은 지지되는 것으로 나타났다. 형태인식과 읽기이해의 관계에서 어휘력의 부분매개 모 형과 표준회귀계수를 도식화 하면 Figure 1과 같다.

\section{논의 및 결론}

본 연구는 형태인식능력이 읽기이해에 어떠한 영향을 미치며 이 관계에서 수용어휘 지식이 매개변인으로 작용하는지를 알아보기 위해 실시되었다. 이를 위하여 초등학생 278명을 대상으로 표준화 된 공식검사의 하위검사인 읽기이해 검사와 수용어휘력 검사를 실 시하였으며, 형태인식 검사는 제작하여 적용하였다. 그 결과 형태인 식은 읽기이해에 유의한 영향을 미치는 것으로 나타났으며, 이 관 계 사이에서 어휘력은 부분매개의 유의한 효과를 보이는 것으로 분석되었다. 이러한 연구결과는 국외 선행연구에서 보고된 바와 부 합하는데(Kirby et al., 2012; Nagy, Carlisle, \& Goodwin, 2014; Wolt- er \& Gibson, 2015) 특히 한국어를 바탕으로 제작된 파생어 형태인 식 검사를 활용한 본 연구에서 해당 가설이 지지됨으로써 관련 영 역의 기초 연구로서 후속연구를 위한 이론적 기초를 제공할 수 있 으리라 기대되었다. 또한 본 연구의 결과를 바탕으로 논의할 점은 다음과 같다.

첫째, 본 연구결과는 형태인식이 읽기이해능력의 향상에 미치는 긍정적인 영향력이 있음을 보고하였다. 선행연구들도 마찬가지로 다양한 언어에서 형태인식이 단어읽기나 철자쓰기와 관련을 보이 거나(Apel \& Werfel, 2014; Saiegh-Hadded \& Geva, 2008; Schiff, \& Raveh, 2007), 형태론적 지식을 증진하는 중재의 직접적인 결과나 메타분석 결과 문해력과 언어발달에 기여한다고 보고함으로써 읽 기이해에 미칠 수 있는 형태인식의 영향력을 긍정하였다(Bowers, Kirby, \& Deacon, 2010; Goodwin \& Ahn, 2013; Nagy et al., 2014). Nagy (2007)는 형태인식이 세 가지 이유에서 읽기이해에 기여한다 고 설명하였다. 첫째, 형태인식이라는 어휘 추론적(lexical inferencing) 특성이 읽기를 하는 동안 복잡한 단어의 의미를 추론하도록 도와 주기 때문이다. 다시 말해 형태인식적 추론기술을 지닌 독자 는 텍스트를 읽으면서 동시에 복잡한 단어의 의미를 분석하여 파 악하는 과정을 진행한다. 즉, '바로 그 자리에서 어휘학습(on the spot vocabulary learning)'(Nagy, 2007, p. 64)을 함으로써 읽기자 료가 지닌 의미의 간극을 메꿀 수 있기에 궁극적으로 더 나은 이해 력을 갖게 된다는 것이다. 두 번째로, 성숙한 형태인식을 지닌 독자 는 파생어 내 접사로부터 통사 단서를 추론할 수 있는데 이는 복잡 한 문장의 구성성분을 이해하는 데에도 도움이 된다. 마지막으로, 형태론적으로 복잡한 단어를 유창하게 해독하는 데에도 긍정적 효과가 있으므로 궁극적으로 읽기자료를 빠르게 이해할 수 있다. 이러한 설명은 읽기자료를 분석하고 통합적으로 이해하도록 중재 하는 교수프로그램을 작성할 때 중요한 시사점을 제시한다. 예컨 대, 교육이나 임상현장에서 진행하는 읽기교수 프로그램에 단어의 구성성분을 분석하고 조작하는 과정인 형태인식 기술을 단원목표 혹은 중재목표로 포함하는 것이다.

둘째, 본 연구결과에 의하면 형태인식이 어휘력을 부분매개로 읽 기이해에 영향을 미치는 것으로 나타났다. 이 결과는 형태인식 기 술이 언어체계의 증진에 기여하며 이를 통해 읽기이해에 긍정적인 영향을 미친다는 선행연구들과 일맥상통한다(Deacon et al., 2014; Levesque et al., 2017). 반면 이 연구들은 어휘력뿐 아니라 단어읽기 기술 등도 함께 분석하여 부분적인 영향력을 보고하였는데 이는 본 연구결과를 바탕으로 좀 더 다양한 변인을 고려한 후속연구를 진행할 때 참고하여야 할 것이다. 어휘력의 향상에 미치는 형태인식 의 효과는 다수의 중재연구를 통해 확인될 수 있다. 일례로 Bowers 
와 Kirby (2010)는 초등 4, 5 학년 교실에서 20 회기 동안 단어의 형태 구조를 교육했는데 그 결과 실험집단 아동들은 이전에 습득한 형 태구조 지식을 적용하여 낮설고 복잡한 파생어의 의미를 해석할 수 있었다. 그 결과를 바탕으로 연구자들은 이제 얼마나 많은 양의 '어휘'를 가르쳐야 하는가에서 얼마나 많은 ‘형태론적 단어군(morphological families)'을 가르쳐야 하는 가로 어휘교수의 틀이 재정 립되어야 한다고 설명하였다. Perfetti (2007)가 제안한 어휘질 가설 (lexical quality hypothesis)에 의하면 단어에 관한 정신적 표상(어 휘표상, lexical representation)이 기억 속 단어에 더 잘 접근할 수 있 도록 영향을 미치는데 이 어휘의 질에 관한 표상은 다섯 가지로 특 징 할 수 있다. 즉, 단어의 정체(identity)를 규정하는 철자, 음운, 문 법, 의미의 네 가지와 그 네 가지 구성요소를 결합(constituent binding)하는 나머지 요인이 그것이다. 형태인식에 관하여 주목하는 연 구자들은 형태론적 지식이 단어 간 및 단어 내 문법지식과 의미지 식을 결합하는 접착제와 같은 역할을 수행할 수 있다고 설명하였 다. 이에 더해 Nagy 등(2013)은 형태인식 중재에 관한 다수의 논문 을 리뷰하면서 형태론적 지식 및 구조에 관한 교수가 특히 낮은 어 휘지식이나 문해기술을 가진 학생들에게 도움이 될 수 있다고 결 론지었다. 단어를 형태소 수준에서 인지하고 분석하며 조작하는 기술은 길고 복잡한 단어를 인식하는 데 어려움을 겪거나 낮은 단 어읽기 기술을 지닌 학생에게 일종의 보완전략이 되고 궁극적으로 읽기자료를 이해하는 데에도 도움을 줄 것이기 때문이다. 종합하자 면 형태인식은 어휘의 의미를 촉진하고 결합함으로써 깊이 있는 어 휘지식을 지니도록 영향을 미치고 이를 통해 읽기이해에 유의한 관 련성을 지닐 뿐 아니라 단어를 읽어내는 해독기술을 지원함으로써 직접적으로 읽기이해에 영향을 미치기도 한다. 국내에서도 초등 저 학년 일반 아동의 어휘수준에 따른 형태인식능력의 유의한 차이를 밝히거나(Chung, 2017), 다문화배경 아동(Kim \& Jung, 2015; Shim \& Chung, 2019), 단순언어장애(Kim \& Choi, 2018) 및 언어학습장 애(Han \& Kim, 2018) 아동을 대상으로 한 형태인식 특성을 탐색 하는 연구가 꾸준히 보고되는 추세이다. 또한 파생어뿐 아니라 한 국어 특성을 반영한 연결어미 형태인식(Chung \& Shim, 2019) 등에 관한 탐색도 진행되나 여전히 형태인식의 중재효과에 관한 국내연 구는 후속연구과제로 남아있다.

본 연구를 진행하면서 나타난 제한점과 후속연구를 위한 제언은 다음과같다.

먼저, Apel과 Diehm (2014)의 연구처럼 아동을 성취수준이나 학 년에 따라 분류하여 형태인식이나 어휘의 특성, 읽기이해에 미치는 관련성과 발달적 추이를 분석하지 못하였다. 후속연구에서는 대상 아동의 수준이나 학년에 따른 분석을 진행하여 저성취 아동이나
장애 아동 집단이 보이는 형태인식의 특성을 밝히거나 학년에 따 른 변인들의 발달적 추이에 관한 비교연구를 진행하기를 희망한다. 둘째, Baron과 Kenny 모형의 간명성과 특성 상 학년이나 연령으로 표본을 통제하지 못하였다. 읽기이해의 예측요인을 탐색한 국내외 연구들은 학년이 높아짐에 따라 읽기이해에 미치는 예측요인이 변 화함을 보고하므로(Chung \& Yoon, 2019; Kim, Petwcher, Schatscheider, \& Foorman, 2010; Nagy et al., 2006) 후속연구에서는 연령 이나 학년을 통제하거나 분석집단을 동질화 할 필요가 있다. 셋째, 본 연구에서는 파생어형태인식의 총점을 사용하였으나, 파생어와 굴절어 등의 다른 형태인식 유형이 개별적으로 미치는 영향력의 크 기를 탐색할 필요도 있다.

\section{REFERENCES}

Anglin, J. M. (1993). Vocabulary development: a morphological analysis. Monographs of the Society for Research in Child Development, 58(1), 1-186.

Apel, K., \& Diehm, E. (2014). Morphological awareness intervention for kindergartners and first and second grade students from low SES homes: a small efficacy study. Journal of Learning Disabilities, 47, 65-75.

Apel, K., \& Lawrence, J. (2011). Contributions of morphological awareness skills to word-level reading and spelling in first-grade children with and without speech sound disorder. Journal of Speech, Language, and Hearing Research, 54, 1312-1327.

Apel, K., \& Werfel, K. (2014). Using morphological awareness instruction to improve written language skills. Language, Speech, and Hearing Services in Schools, 45(4), 251-260.

Baron, R. M., \& Kenny, D. A. (1986). The moderator-mediator variable distinction in social psychological research: conceptual, strategic, and statistical considerations. Journal of Personality and Social Psychology, 51(6), 11731182.

Berninger, V. W., Abbott, R. D., Nagy, W., \& Carlisle, J. (2010). Growth in phonological, orthographic, and morphological awareness in grades 1 to 6 . Journal of Psycholinguistic Research, 39(2), 141-163.

Binder, K. S., Cote, N. G., Lee, C., Bessette, E., \& Vu, H. (2017). Beyond breadth: the contributions of vocabulary depth to reading comprehension among skilled readers. Journal of Research in Reading, 40(3), 333-343.

Bowers, P. N., \& Kirby, J. R. (2010). Effects of morphological instruction on vocabulary acquisition. Reading and Writing, 23(5), 515-537.

Bowers, P. N., Kirby, J. R., \& Deacon, H. (2010). The effects of morphological instruction on literacy skills: a systematic review of the literature. Review 
of Educational Research, 80(2), 144-179.

Cain, K., \& Oakhill, J. (2014). Reading comprehension and vocabulary: is vocabulary more important for some aspects of comprehension? Topics in Cognitive Psychology, 114(4), 647-662.

Carlisle, J. F. (2010). Effects of instruction in morphological awareness on literacy achievement: an integrative review. Review of Research Quarterly, 45(4), 464-487.

Casalis, S., Deacon, S. H., \& Pacton, S. (2011). How specific is the connection between morphological awareness and spelling? a study of French children. Applied Psycholinguistics, 32(3), 499-511.

Chung, B. (2016). Morphological awareness on derivational affixes and related variables in school-aged children (Doctoral Dissertation). Ewha Womans University, Seoul, Korea.

Chung, B. (2017). Relations between morphological awareness and vocabulary in first and second graders. Journal of Learner-Centered Curriculum and Instruction, 17(9), 541-552.

Chung, B., Kim, Y. T., \& Yoon, H. J. (2017). Relative contributions of components to different reading comprehension tasks in grade 3-5. Communication Sciences \& Disorders, 27(1), 66-75.

Chung, B., \& Shim, S. (2019). Morphological awareness of connective endings in 1st through 4th grade children with and without language delay from culturally diverse families. Communication Sciences \& Disorders, 24(2), 367-378.

Chung, B., \& Yoon, H. (2019). Contributions of related variables to reading comprehension in school-age children: a two-year longitudinal study. Communication Sciences \& Disorders, 24(3), 636-646.

Deacon, S. H., Kieffer, M. J., \& Laroche, A. (2014). The relation between morphological awareness and reading comprehension: evidence from mediation and longitudinal models. Scientific Studies of Reading, 18(6), 432-451.

Deacon, S. H., \& Kirby, J. R. (2004). Morphological awareness: just "more phonological?" the roles of morphological and phonological awareness in reading development. Applied Psycholinguistics, 25(2), 223-238.

Gibson, F. E., \& Wolter, J. A. (2015). Morphological awareness intervention to improve vocabulary and reading success. Perspectives on Language Learning and Education, 22(4), 147-155.

Goodwin, A. P., \& Ahn, S. (2013). A meta-analysis of morphological intervention in English: effects on literacy outcomes for school-age children. Scientific Studies of Reading, 17(4), 257-285.

Han, H. J., \& Kim, M. B. (2018). Correlation among morphological awareness, reading fluency and spelling for school-aged children with language- learning disabilities in third to fourth grades. Communication Sciences \& Disorders, 23(2), 347-359.

Hoff, E. (2014). Language development. Belmont, CA: Cengage Learning.

Kieffer, M. J., \& Lesaux, N. K. (2012). Development of morphological awareness and vocabulary knowledge in Spanish-speaking language minority learners: a parallel process latent growth curve model. Applied Psycholinguistics, 33(1), 23-54.

Kim, S. A., \& Choi, S. Y. (2018). Morphological awareness abilities of children with specific language impairment in upper grades of elementary school. Journal of Speech-Language \& Hearing Disorders, 27(4), 19-30.

Kim, Y. T., Hong, G. H., Kim, G. H., Jang, H. S., \& Lee, J. Y. (2009). Receptive and Expressive Vocabulary Test (REVT). Seoul: Seoul Community Rehabilitation Center.

Kim, E. H., \& Jung, K. H. (2015). Morphological awareness of 1st to 3rd grade school-aged children from multicultural families. Communication Sciences \& Disorders, 20(2), 319-330.

Kim, Y. S., Petscher, Y., Schataschneider, C., \& Forrman, B. (2010). Does growth rate in oral reading fluency matter in predicting reading comprehension achievement? Journal of Educational Psychology, 102(3), 652-667.

Kirby, J. R., Deacon, H., Bowers, P. N., Izenberg, L., Wade-Woolley, L., \& Parrila, R. (2012). Children's morphological awareness and reading ability. Reading and Writing, 25(2), 389-410.

Kirby, J. R., Desrochers, A., Roth, L., \& Lai, S. S. V. (2008). Longitudinal predictors of word reading development. Canadian Psychology, 49(2), 103-110.

Levesque, K. C., Kieffer, M. J., \& Deacon, H. (2017). Morphological awareness and reading comprehension: examining mediating factors. Journal of Experimental Child Psychology, 160, 1-20.

McKeown, M. G., Beck, I. L., Omanson, R. C., \& Perfetti, C. A. (1983). The effects of long-term vocabulary instruction on reading comprehension: a replication. Journal of Reading Behavior, 15(1), 3-18.

Nagy, W. E. (2007). Metalinguistic awareness and the vocabulary-comprehension connection. In Wagner, R. R, K., Muse, A. E., Tannenbaum, K. R.(Eds), Vocabulary acquisition and its implications for reading comprehension (pp. 52-77). New York: Guilford.

Nagy, W. E., Berninger, V. W., \& Abbott, R. D. (2006). Contributions of morphology beyond phonology to literacy outcomes of upper elementary and middle school students. Journal of Educational Psychology, 98(1), 134-147.

Nagy, W. E., Carlisle, J. F., \& Goodwin, A. P. (2014). Morphological knowledge and literacy acquisition. Journal of Learning Disabilities, 47(1), 3-12. Nagy, W., \& Scott, J. (2000). Vocabulary process. In M. Kamil et al. (Eds.), Hand- 
book of reading research Volume III (pp. 269-284). Muhwah, NJ: Lawrence Erlbaum Associates.

Pae, S., Kim, M., Yoon, H. J., \& Jang, S. (2015). Korean Language based Reading Assessment (KOLRA). Seoul: Hakjisa.

Park, H. (2014). Korean version of Comprehensive Test of Nonverbal Intelligence-second edition (K-CTONI-2). Seoul: Mindpress.

Perfetti, C. A. (2007). Reading ability: lexical quality to comprehension. Scientific Studies of Reading, 11(4), 357-383.

Perfetti, C. A., Landi, N., \& Oakhill, J. (2005). The acquisition of reading comprehension skill. In M. J. Snowling \& C. Hulme (Eds.), Handbook of Developmental Psychology (pp. 209-226). Malden, MA: Blackwell Publishing.

Ramirez, G., Walton, P., \& Roberts, W. (2013). Morphological awareness and vocabulary development among kindergarteners with different ability levels. Journal of Learning Disabilities, 47(1), 54-64.

Roth, F., Speech, D., \& Cooper, D. (2002). A longitudinal analysis of the connection between oral language and early reading. Journal of Educational Research, 95(5), 259-272.

Saiegh-Haddad, E., \& Geva, E. (2008). Morphological awareness, phonological awareness, and reading in English-Arabic bilingual children. Reading and Writing, 21(5), 481-504.

Schiff, R., \& Raveh, M. (2007). Deficient morphological processing in adults with developmental dyslexia: another barrier to efficient word recognition? Dyslexia, 13(2), 110-129.

Shim, S. E., \& Chung, B. (2019). Morphological awareness of connective endings in 1st through 4grade children with and without language delay from culturally diverse families. Communication Sciences \& Disorders, 24(2), 367-378.

Sparks, E., \& Deacon, S. H. (2015). Morphological awareness and vocabulary acquisition: a longitudinal examination of their relationship in Englishspeaking children. Applied Psycholinguistics, 36(2), 299-321.

Storch, S. A., \& Whitehurst, G. J., (2002). Oral language and code-related precursors to reading: evidence from a longitudinal structural model. Developmental Psychology, 38(6), 934-947.

Tambyraja, S. R., Schmitt, M. B., Farquharson, K., \& Justice, L. M. (2015). Stability of language and literacy profiles of children with language impairment in the public schools. Journal of Speech, Language, Hearing Research, 58(4), 1167-1181.

Tong, X., Deacon, S. H., Kirby, J. R., Cain, K., \& Parrila, R. (2011). Morphological awareness: a key to understanding poor reading comprehension in English. Journal of Educational Psychology, 103(3), 523-534.

Wolter, J. A., \& Gibson, F. E. (2015). Morphological awareness assessment and intervention to improve language and literacy. Seminars in Speech and Language, 36(1), 31-41.

Yoon, H., Pae, S., \& Chung, B. (2018). The role of vocabulary breadth and depth on reading comprehension in grade 1-4. Communication Sciences \& Disorders, 23(2), 519-527.

Zhang, H. (2014). Morphological awareness in vocabulary acquisition among Chinese-speaking children: testing partial mediation via lexical inference ability. Reading Research Quarterly, 50(1), 129-142. 


\section{국문초록}

\section{초등학생의 형태인식과 읽기이해의 관계에서 어휘력의 매개효과 \\ 정부자}

조선대학교 언어치료학과

배경 및 목적: 형태인식이란 언어의 형식과 구조를 이해하고, 분석하며, 의미를 적용하는 능력으로 심상에 저장된 어휘들을 서로 결합 하도록 돕는 메타언어능력을 의미한다. 또한 어휘의 증진에 기여함으로써 직간접적으로 읽기자료의 이해에도 영향을 미친다. 본 연구 는 형태인식과 읽기이해에 미치는 어휘력의 매개효과를 측정하고자 하였다. 방법: 초등 1-6학년 중 연구의 조건에 적합하고 비언어지능 70 이상에 해당하는 아동 278명을 대상으로 파생어 형태인식검사, 수용어휘검사, 읽기이해검사를 실시하였다. 읽기이해를 종속변인으 로 Baron \& Kanny가 제안한 회귀분석을 통해 매개변인 검증절차를 적용하였고, 매개효과의 유의성 검정을 위해 Sobel Test를 실시하 였다. 결과: 연구결과 파생어 형태인식은 읽기이해에 유의한 영향을 미치는 것으로 나타났으며, 이 관계에서 어휘력은 부분매개의 유의 한 효과를 보이는 것으로 분석되었다. 이로써 국외 선행연구에서 밝혀졌던 어휘력과 읽기이해에 미치는 형태론적 지식의 긍정적인 영 향력이 한국어 파생어를 사용한 형태인식연구에서도 유의함을 시사하였다. 논의 및 결론: 형태인식기술은 어휘 추론적 특성을 지니므 로 어휘질 가설에서 제시하는 깊이 있는 어휘습득에 기여하며, 특히 낮은 어휘지식이나 문해기술을 지닌 아동에게 긍정적인 도움을 줄 수 있을 것이다. 이러한 결과를 바탕으로 본 연구의 시사점과 제한점 및 후속연구를 위한 제언을 하였다.

핵심어: 읽기이해, 형태인식, 어휘력, 초등학생, 매개변인

이 논문은 2019학년도 조선대학교 학술연구비의 지원을 받아 연구되었음.

\section{참고문헌}

김영태, 홍경훈, 김경희, 장혜성, 이주연(2009). 수용·표현어휘력검사(REVT). 서울: 서울장애인종합복지관.

김은하, 정경희(2015). 초등 1-3학년 다문화가정 아동의 형태소 인식능력. Communication Sciences \& Disorders, 20(2), 319-330.

김선아, 최소영(2018). 초등학교 고학년 단순언어장애 아동의 형태소인식 능력. 언어치료연구, 27(4), 19-30.

박혜원(2014). 한국 비언어지능검사 2판(K-CTONI-2). 서울: 마인드프레스.

배소영, 김미배, 윤효진, 장승민(2015). 한국어읽기검사(KOLRA). 서울: 학지사.

심승은, 정부자(2019). 초등학교 1-4학년 다문화가정아동의 연결어미 형태인식 특성. Communication Sciences \& Disorders, 24(2), 367-378.

윤효진, 배소영, 정부자(2018). 초등 1-4학년 아동의 읽기이해능력에서 어휘지식의 양과 깊이의 역할. Communication Sciences \& Disorders, 23(2),

519-527.

정부자(2016). 초등학교 저학년과 중학년 일반아동의 파생어 형태인식 발달 및 예측변인 탐색. 이화여자대학교 대학원 박사학위 논문.

정부자(2017). 초등학교 1-2학년 아동의 어휘력에 따른 형태인식 특성. 학습자중심교과교육연구, 17(9), 541-552.

정부자, 김영태, 윤효진(2017). 읽기이해검사의 형식에 따른 관련 요인 탐색: 초등학교 3-4학년을 대상으로. Communication Sciences \& Disorders,

22(1), 66-75.

정부자, 심승은(2019). 초등 1-4학년 아동의 형태인식 유형에 따른 어휘, 구문 및 읽기 특성. 언어치료연구, 28(3), 51-59.

정부자, 윤효진(2019). 초등학교 저학년과 중학년의 읽기이해 관련 변인에 관한 종단연구. Communication Sciences \& Disorders, 24(3), 636-646. 한효정, 김미배(2018). 초등 3-4학년 언어학습장애아동의 형태소 인식능력과 읽기 유창성, 철자쓰기 간의 상관관계. Communication Sciences \&

Disorders, 23(2), 347-359.

\section{ORCID}

정부자(제1저자, 교신저자, 교수 https://orcid.org/0000-0002-6158-6637) 